University of Nebraska - Lincoln

DigitalCommons@University of Nebraska - Lincoln

December 1993

\title{
The structural homogeneity of boron carbide thin films fabricated using plasma-enhanced chemical vapor deposition from $\mathrm{B}_{5} \mathrm{H}_{9}+\mathrm{CH}_{4}$
}

Sunwoo Lee

Syracuse University

J. Mazurowski

Syracuse University

W.L. O'Brien

University of Tennessee, Knoxville

Q.Y. Dong

University of Tennessee, Knoxville

J.J. Jia

University of Tennessee, Knoxville

See next page for additional authors

Follow this and additional works at: https://digitalcommons.unl.edu/physicsdowben

Part of the Physics Commons

Lee, Sunwoo; Mazurowski, J.; O'Brien, W.L.; Dong, Q.Y.; Jia, J.J.; Callcott, T.A.; Miyano, K.E.; Ederer, D.L.; Mueller, D.R.; and Dowben, Peter A., "The structural homogeneity of boron carbide thin films fabricated using plasma-enhanced chemical vapor deposition from $\mathrm{B}_{5} \mathrm{H}_{9}{ }^{+} \mathrm{CH}_{4}$ " (1993). Peter Dowben Publications. 99.

https://digitalcommons.unl.edu/physicsdowben/99

This Article is brought to you for free and open access by the Research Papers in Physics and Astronomy at DigitalCommons@University of Nebraska - Lincoln. It has been accepted for inclusion in Peter Dowben Publications by an authorized administrator of DigitalCommons@University of Nebraska - Lincoln. 


\section{Authors}

Sunwoo Lee, J. Mazurowski, W.L. O'Brien, Q.Y. Dong, J.J. Jia, T.A. Callcott, K.E. Miyano, D.L. Ederer, D.R. Mueller, and Peter A. Dowben 


\section{The structural homogeneity of boron carbide thin films fabricated using plasma-enhanced chemical vapor deposition from $\mathrm{B}_{5} \mathrm{H}_{9}+\mathrm{CH}_{4}$}

Sunwoo Lee and J. Mazurowski

Department of Physics and the Solid State Science \& Technology Program, Syracuse University, Syracuse, New York 13244-1130

W. L. O'Brien, Q. Y. Dong, J. J. Jia, and T. A. Callcott

Department of Physics, University of Tennessee, Knoxville, Tennessee 37996

Yexin Tan

Department of Chemistry, Syracuse University, Syracuse, New York 13244-4100

K. E. Miyano and D. L. Ederer

Department of Physics, Tulane University, New Orleans, Louisiana 70118

D. R. Mueller

National Institute of Standards \& Technology, Gaithersburg, Maryland 20899

P. A. Dowben ${ }^{\text {a) }}$

Department of Physics and the Solid State Science \& Technology Program, Syracuse University, Syracuse, New York 13244-1130 and Center for Materials Research \& Analysis and Department of Physics,

University of Nebraska-Lincoln, Lincoln, Nebraska 68588-0111

(Received 8 March 1993; accepted for publication 21 August 1993)

Boron carbide thin films of several $\mathrm{B} / \mathrm{C}$ ratios have been deposited on $\mathrm{Si}(111)$ using plasma-enhanced chemical vapor deposition from nido-pentaborane $(9)\left(\mathrm{B}_{5} \mathrm{H}_{9}\right)$ and methane $\left(\mathrm{CH}_{4}\right)$. X-ray diffraction studies of boron carbide thin films on $\mathrm{Si}(111)$ exhibited characteristic microcrystalline diffraction lines. Soft $x$-ray emission spectroscopy was used to verify that the local electronic structure and composition of each sample corresponded to a homogeneous solid solution boron carbide phase.

\section{INTRODUCTION}

We have made a boron carbide material by plasmaenhanced chemical vapor deposition with a resistivity 10 orders of magnitude greater than other boron carbide alloys. ${ }^{1}$ With the new form of boron carbide fabricated using plasma-enhanced thin film deposition (with boranes or carboranes with an alkane as the chemical sources) a material suitable for electronic devices was produced ${ }^{2}$ and the first heterojunction boron carbide diodes have now been made. ${ }^{1,3}$ The microstructure of this material, therefore, is of great interest.

In general, the microstructure and composition of boron carbide phases have been the subject of much investigation and bulk single crystals, polycrystalline samples, ${ }^{4-14}$ and thin films ${ }^{15-19}$ have been studied. The compositional homogeneity of boron carbide has been shown to be sensitive to both sample preparation techniques and composition (boron-to-carbon ratio). ${ }^{20}$ It is essential to assess the structural homogeneity and the amount of free carbon in order to understand the semiconductor properties of plasma-enhanced chemical vapor deposited (PECVD) thin film boron carbide. Free carbon can degrade the film quality and increase conductivity. ${ }^{21}$ In this article, we demonstrate that boron carbide thin films fabricated from $\mathrm{B}_{5} \mathrm{H}_{9}+\mathrm{CH}_{4}$ by PECVD are compositionally uniform and

a) Address correspondence to this author. have a microcrystalline structure. The local electronic structure of boron carbide films on $\mathrm{Si}$ is also discussed and can be correlated with the boron-to-carbon ratio.

\section{EXPERIMENT}

Boron carbide thin films were grown on $\mathrm{Si}(111)$. Deposition of the films was undertaken at about $400{ }^{\circ} \mathrm{C}$ in a custom designed parallel plate $13.56 \mathrm{MHz}$ radio-frequency PECVD reactor described previously. ${ }^{2}$ The composition of the film was controlled by adjusting the partial pressure ratio of nido-pentaborane $(9)\left(\mathrm{B}_{5} \mathrm{H}_{9}\right)$ and methane $\left(\mathrm{CH}_{4}\right)$. Films of different thickness from 0.1 to $1.0 \mu \mathrm{m}$ were made. The composition and thickness of boron carbide thin films were determined using Auger electron spectroscopy and a profilometer. The Auger electron spectroscopy results were calibrated against a $\mathrm{B}_{4} \mathrm{C}\left(\mathrm{B}_{0.75} \mathrm{C}_{0.25}\right)$ standard. Boron carbides over the composition range from 2.4 to 50 boron-tocarbon ratio were obtained.

$X$-ray diffraction (XRD) experiments were performed using a Phillips model PW1729 diffractometer and a General Electric model XRD-5 diffractometer with copper $K \alpha$ radiation. Specimens were scanned through $2 \theta$ angles ranging from $10^{\circ}$ to $100^{\circ}$. Reflection high energy electron diffractometry (RHEED) ( $\left.E_{0}=100 \mathrm{keV}\right)$ was also employed in an effort to characterize the structure of the surface region of the boron carbide thin films.

Soft $x$-ray emission spectroscopy (SXES) was em- 
ployed as a probe of the composition and the local electronic structure of boron carbide films on silicon substrates. In x-ray emission spectroscopy an electron or a photon beam is used to generate vacancies in the core levels of atoms within a sample. Determination of the energy distribution of the $x$ rays emitted as electrons drop into core-level vacancies from occupied valence states depends upon calculating the product of the matrix elements connecting the initial core vacancy with the valence states. Aside from a factor of photon energy cubed (which arises from the photon density of states and the dipole approximation) the matrix element connecting the initial and final states is often only weakly energy dependent, particularly if states of one angular momentum symmetry are probed.

The soft $\mathrm{x}$-ray emission spectra were obtained on beamline U-10A at the National Synchrotron Light Source at Brookhaven National Laboratory. The apparatus installed there incorporates facilities to generate core vacancies within a sample by employing either an incident electron beam $(0.5-5 \mathrm{keV})$, white light, or monochromatized synchrotron radiation (100-500 eV). In the present experiment a $3 \mathrm{keV}$ electron beam at a current density of about $10 \mu \mathrm{A} /(\mathrm{mm})^{2}$ was used to generate the initial core vacancies. Light emitted from the sample was energy analyzed by a grating spectrometer and computer-interfaced multichannel detector. The instrumentation has been described in more detail elsewhere. ${ }^{22-24}$ The spectrometer resolution was about $0.5 \mathrm{eV}$ in the range of the boron emission and 1 $\mathrm{eV}$ in the range of the carbon emission. The experiments were executed at room temperature and under ultrahigh vacuum conditions.

\section{RESULTS AND DISCUSSION}

\section{A. Film composition}

A wide range of stoichiometries $(0.29<B / C<49$, or $0.02<x<0.29$ in $B_{1-x} C_{x}$ ) of boron carbide was obtained in this experiment (by adjusting the partial pressure ratio between $\mathrm{B}_{5} \mathrm{H}_{9}$ and $\mathrm{CH}_{4}$ ) as determined by Auger electron spectroscopy. ${ }^{1}$ Figure 1 shows a correlation between the partial pressure ratio of reactants and the boron-to-carbon ratio for the resulting films determined by Auger electron spectroscopy (AES) and SXES. The log of the composition ratio of boron-to-carbon varies linearly with the log of the partial pressure ratio of reactants, as indicated by both AES and SXES measurements; i.e., there is a power law relationship with exponent of 1.5 . Although systematic errors that occur as a result of experimental parameters (such as sample annealing temperature, plasma power, and total reactants pressures) are not fully understood, nonetheless for a single set of parameter conditions, the correlation between partial pressures and film composition can be easily identified as seen in the inset to Fig. 1. The film composition is not directly proportional to the composition of the reactant gases even when available boron and carbon atom numbers are considered. This observation may reflect surface reactions including carborane cluster formation ini-
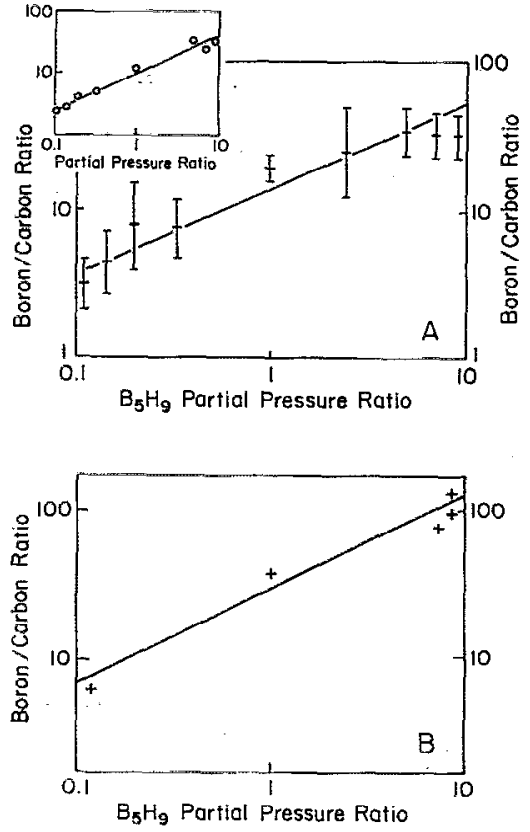

FIG. 1. Boron-to-carbon ratios determined by Auger electron spectroscopy are plotted against the ratio of $\mathrm{B}_{5} \mathrm{H}_{9}$ to $\mathrm{CH}_{4}$ partial pressures (A). The correlation is shown for one specific plasma geometry and fixed conditions in the inset showing that errors are essentially systematic. Boron $1 s$ is carbon $1 s$ intensity ratios from the soft $\mathrm{x}$-ray emission spectroscopy are used to estimated the boron-to-carbon ratio plotted against the ratios of $\mathrm{B}_{5} \mathrm{H}_{9}$ to $\mathrm{CH}_{4}$ partial pressures (B). The results are in good agreement.

tiated during the deposition process, or gas phase plasma initiated chemistry. Such reactions have been observed ${ }^{25}$ and have been previously suggested. ${ }^{1,2}$

An Auger electron spectrum for a typical film is shown in Fig. 2. By sputtering the films at a fixed rate, the film composition profiles were generated. The concentration of boron and carbon was seen to be very uniform throughout

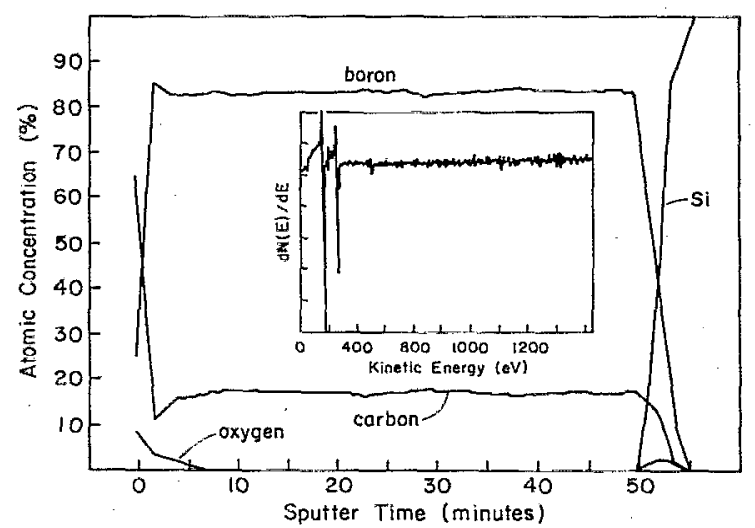

FIG. 2. An Auger electron spectroscopy depth profile of boron, carbon, oxygen, and silicon of a boron carbide film fabricated from $\mathrm{B}_{5} \mathrm{H}_{9}$ and $\mathrm{CH}_{4}$ deposited in a $20 \mathrm{~W}$ plasma reactor on $\mathrm{Si}(111)$. Atomic percent composition is plotted against $\mathrm{Ar}^{+}$ion sputtering time. Auger electron spectra of boron carbide fabricated from $440 \mathrm{mTorr}$ of $\mathrm{CH}_{4}$ and $60 \mathrm{mTorr}$ of $\mathrm{B}_{5} \mathrm{H}_{9}$ in a $20 \mathrm{~W}$ rf plasma is shown in the inset. 


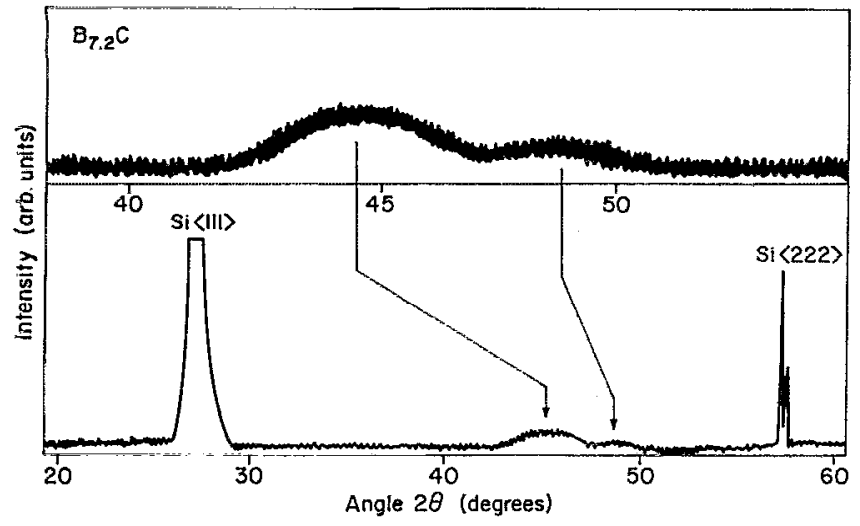

FIG. 3. Broad peak of diffraction pattern for $\mathrm{B}_{7,2} \mathrm{C}$ on $\mathrm{Si}(111)$ is shown in the $2 \theta$ range from $20^{\circ}$ to $60^{\circ}$. Large sharp peaks are identified as $\mathrm{Si}\langle 111\rangle, \mathrm{Si}\langle 222\rangle$, respectively, as indicated at bottom. Boron carbide features are emphasized at top.

the film. No minor impurities were observed except perhaps for hydrogen from source gases and a small amount of oxygen. The oxygen peak was found upon exposing the films to air. Since Auger electron spectroscopy is insensitive to hydrogen, elemental analysis by flash pyrolysis was undertaken; elemental analysis of very thick films indicated that the hydrogen impurity level was less than $6 \% .^{26}$ The very low dc electrical conductivity of these and other films of this boron carbide ${ }^{1}$ suggests that the material is homogeneous and single phase since nonbonded free carbon often degrades the electronic properties of boron carbide. The AES line shapes were found to be insensitive to compositions as noted in the previous studies. ${ }^{27}$

\section{B. Microstructure of the thin films}

$\mathrm{X}$-ray diffraction spectra of thick $(\geqslant 1, \mu \mathrm{m})$ $\mathrm{B}_{7.2} \mathrm{C}\left(\mathrm{B}_{0.88} \mathrm{C}_{0.12}\right)$ deposited on $\mathrm{Si}(111)$ exhibit broad diffraction lines in the range $42^{\circ}<2 \theta \leqslant 50^{\circ}$ (Fig. 3 ). The intensity of the features is relatively small due to the low scattering factors for boron and carbon. The diffraction pattern was obtained using copper $K \alpha$ radiation $(\lambda=1.54 \AA)$. The homogeneous boron carbide phase produced by PECVD is easily distinguished from the silicon substrate. Calculated $d$-spacing values corresponding to the maxima are 2.03 and $1.87 \AA$, respectively. The $d$-spacing values for thin film boron carbide are smaller than the reported value $(2.74 \AA$ ) for $\alpha$-rhombohedral bulk boron carbide fabricated by hotpressing or high temperature CVD, ${ }^{-9,15-17}$ but the bond length of $1.7-1.8 \AA$ is typical for boranes and carboranes ${ }^{28}$ as well as boron carbide phases. ${ }^{6-13}$

The microstructure of boron carbide on $\mathrm{Si}(100)$ made by PECVD from diborane $\left(\mathrm{B}_{2} \mathrm{H}_{6}\right)$, has been investigated and inclusions of hydrogen and helium have been reported. ${ }^{29,30}$ There is a transition temperature in the range of $730-800^{\circ} \mathrm{C}$ between an amorphous and a microcrystalline structure. ${ }^{30}$ Films grown from nido-pentaborane(9) $\left(\mathrm{B}_{5} \mathrm{H}_{9}\right)$ exhibit $\mathrm{x}$-ray diffraction patterns more characteristic of microcrystalline or polycrystalline boron carbide. The reflection high energy electron diffraction (RHEED)

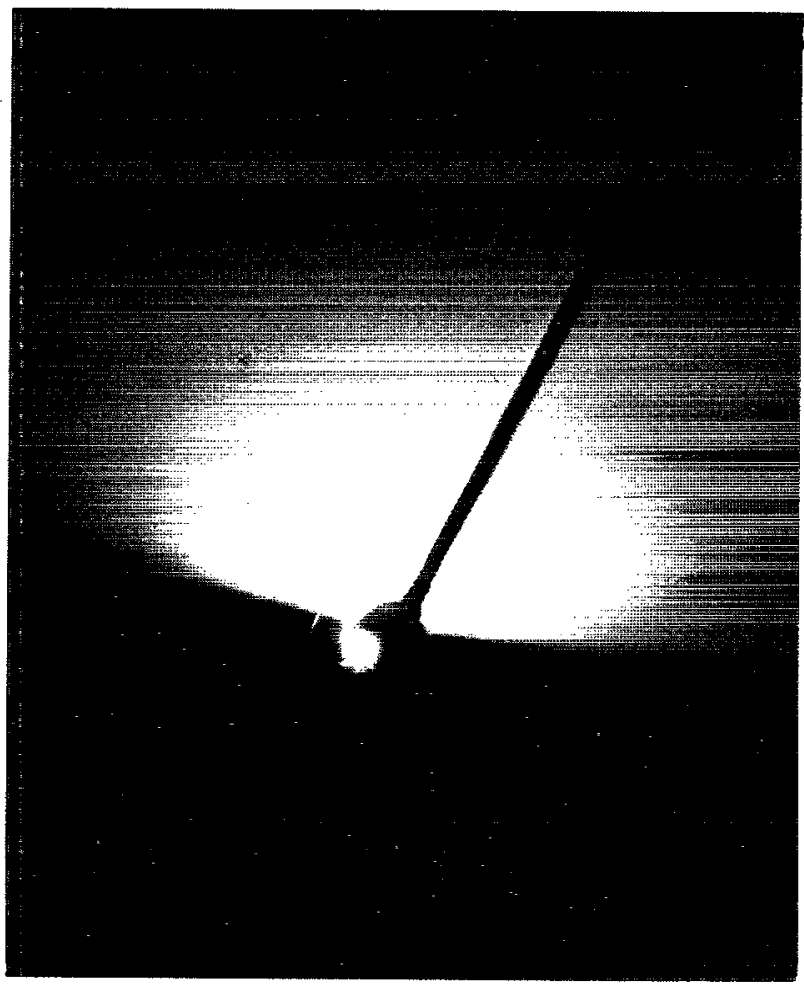

FIG. 4. Reflection high energy electron diffraction (RHEED) pattern for $B_{7.2} \mathrm{C}$ on $\mathrm{Si}(111)$ shows an amorphous structure for the surface of the boron carbide film.

pattern indicates a pattern characteristic of an amorphous film (Fig. 4). The full width at half maximum (FWHM) of the x-ray diffraction lines for microcrystalline boron carbide is inversely proportional to the average grain size of the microcrystallites. The grain size calculated from the broadening in our diffraction data is about $30-40 \AA$ based on Scherrer's formula. ${ }^{31}$

Our deposition temperature (about $400^{\circ} \mathrm{C}$ ) using nido-pentaborane (9) is quite low compared with the deposition temperatures previously required to produce microcrystalline rather than amorphous structure using diborane $\left(730^{\circ} \mathrm{C}-800^{\circ} \mathrm{C}\right)$. It is known that atomic hydrogen enhances the formation of microcrystalline silicon even at substrate temperatures of $100^{\circ} \mathrm{C}$ as a result of the influence of atomic hydrogen on surface kinetics. ${ }^{32}$ Structural differences between the two boranes and the differences in hydrogen content of the two boranes could result in substantially different surface kinetics for $\mathrm{B}_{5} \mathrm{H}_{9}+\mathrm{CH}_{4}$ as opposed to $\mathrm{B}_{2} \mathrm{H}_{6}+\mathrm{He}+\mathrm{H}_{2}$ under similar experimental conditions.

\section{The local electronic structure of boron carbide films}

The local electronic structure of boron carbide films of various compositions was studied using SXES. Transitions into carbon and boron $K$ shell $(1 s)$ initial vacancies were examined in the present experiment. Soft $x$-ray emission spectra are sensitive only to states with angular momentum quantum numbers separated by one from those of the ini- 
tial core vacancy states because the soft $x$-ray emission process obeys the dipole selection rule. Thus, for radiative transitions into initial vacancies in carbon $K$ and boron $K$ levels ( $s$ states) a measure of the $p$-type local density of states at the carbon and boron sites, respectively, is obtained.

Soft $x$-ray emission is insensitive to sample charging, which complicates photoelectron studies of boron carbide films (the resistivity is of the order of $10^{10} \Omega \mathrm{cm}$ at room temperature in our material) since photons are detected rather than low energy electrons. Soft $x$-ray emission spectroscopy is also less surface sensitive than photoelectron spectroscopy because the soft $\mathrm{x}$-ray photons have a longer absorption length in solids than the mean free path of low energy electrons. Crisp ${ }^{33}$ has presented formulae that can be used to estimate the average depth into a material from which electron-beam-excited soft $\mathrm{X}$-ray emission spectra originate. Applying these expressions to the case of $\mathrm{B}_{4} \mathrm{C}$ $\left(B_{0.75} C_{0.25}\right)$ excited by a $3 \mathrm{keV}$ electron beam in the experimental geometry employed, we predicted that the emission spectra originated at an average depth of about $400 \AA$. The required photon absorption lengths were estimated from the density of $\mathrm{B}_{4} \mathrm{C}\left(\mathrm{B}_{0.75} \mathrm{C}_{0.25}\right)$ and atomic cross section data. ${ }^{34}$ Several phenomena can alter or complicate the interpretation of soft $x$-ray emission spectra, including the energy dependence of the spectrometer response, reabsorption of radiation emitted within the sample (selfabsorption), and satellite emission features. All data presented here have been corrected for the energy dependence of the spectrometer sensitivity that was determined by comparing the measured bremsstrahlung profile with the expected profile. ${ }^{35}$ In any event the spectrometer response does not vary significantly over the relatively narrow energy range of boron and carbon valence emission bands (about $8 \%$ for boron and 3\% for carbon). The valence emission is consequently insensitive to slight errors within our knowledge of the spectrometer response. The emission spectra presented have not been corrected for sample selfabsorption. A correction factor to take into account the reabsorption of soft $x$ rays within the sample can be expressed in terms of integral of $\phi(\rho z)$ the intensity of x-ray production as a function of mass depth ${ }^{33}$ and the absorption coefficient as follows:

$$
\begin{aligned}
I_{\text {corrected }}= & I_{\text {measured }}\left(\int \phi\left[\rho \sec \left(\theta_{i}\right) z\right] d z\right) / \\
& \left(\int \phi\left[\rho \operatorname{cosec}\left(\theta_{i}\right) z\right] \exp \left[-\mu \sec \left(\theta_{0}\right) z\right] d z\right),
\end{aligned}
$$

where $\theta_{i}$ is the angle between the surface normal of the sample and the incident radiation beam, $\theta_{0}$ is the angle between the surface normal of the sample and the detector, and $\mu$ is the absorption coefficient for the outgoing $\mathrm{x}$ rays. In the soft $x$-ray region examined in this work an energydependent estimate of the x-ray absorption coefficient $\mu$ for a compound can be made using atomic photoionization cross section data ${ }^{34}$ and the sample density. Evaluating the integrals in the equation we estimate that $6 \%$ of boron $K$ emission generated within the sample is absorbed before it

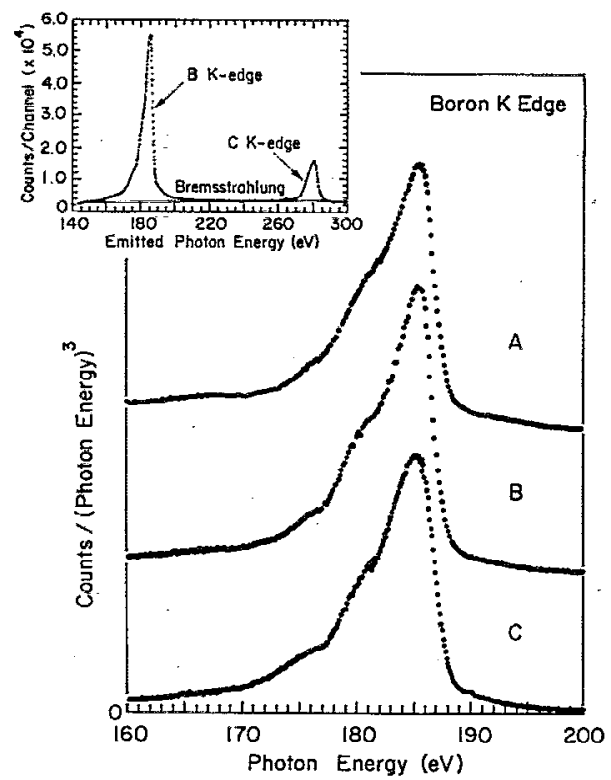

FIG. 5. Comparison of the boron $K$-emission spectra from the various films indicated as sample $\mathrm{A}, \mathrm{B}_{5} \mathrm{H}_{9}: \mathrm{CH}_{4}=9: 1$; sample $\mathrm{B}, \mathrm{B}_{5} \mathrm{H}_{9}: \mathrm{CH}_{4}=1: 1$; sample $\mathrm{C}, \mathrm{B}_{5} \mathrm{H}_{9}: \mathrm{CH}_{4}=1: 9$. The curves have been offset along the vertical axis for clarity and have been normalized to have the same integrated boron emission intensity. The inset shows that the emitted photon intensity as a function of emitted photon energy from film $\mathrm{C}$ in the region of the boron and carbon $K$-emission spectra. The emission spectrum includes a contribution from bremsstrahlung emission as is evident from the intensity in the region between the valence $\rightarrow$ boron $1 s$ and valence $\rightarrow$ carbon $1 s$ transitions.

travels to the detector, while $30 \%$ of carbon $K$ emission is self-absorbed. Over the limited energy range of the emission bands the variation in the fraction of the radiation that is self-absorbed is, however, much smaller. From 270 to $284 \mathrm{eV}$, the energy range of $\mathrm{C} 1 s$ to valence transitions, the correction factor varies by approximately $4 \%$. In the region of the boron emission band this effect is even smaller. Due to the small size of the effect, no correction for selfabsorption was applied to the valence emission data presented.

The boron $K$ edge soft $\mathrm{x}$-ray emission spectra for several film compositions are illustrated in Fig. 5. The spectra are presented following background subtraction and correction for spectrometer response, and following division by a factor of photon energy cubed to take into account the photon energy dependence of the $x$-ray transition rate within the dipole approximation. The ordinates of the plot are proportional to boron $p$-type partial density of states in the samples. The inset in Fig. 5 shows that the boron and carbon $K$-emission spectra for sample $\mathrm{C}\left(\mathrm{B}_{5} \mathrm{H}_{9}: \mathrm{CH}_{4}=1.9\right)$ ride on a bremsstrahlung background modified by the energy dependence of the spectrometer response. The spectra have been normalized to have the same integrated boron emission intensity. Similar $p$-type local density of states information is available at the carbon site from the carbon emission data as illustrated in Fig. 6. The carbon emission spectra for the boron carbide films examined here differ from that of graphite, ${ }^{36}$ both in shape and in the location of 


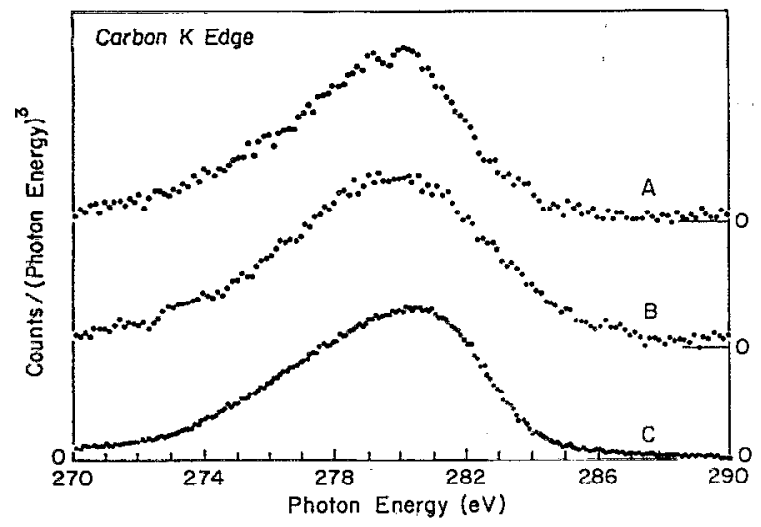

FIG. 6. Comparison of the carbon $K^{\prime}$-emission spectra from the various films as indicated in Fig. 5. The curves have been offset along the vertical axis for clarity and have been normalized to have the same integrated carbon emission intensity.

the maximum emission intensity. The boron spectra are rather similar to that of pure boron ${ }^{37}$ as is consistent with the relatively high values of boron/carbon ratio noted in Fig. 1. The spectral line shapes are not strongly dependent on sample composition. The apparent fine structure in the films with only $1 \%-2 \%$ carbon (spectrum A of Fig. 6) is a consequence of the low signal (spectra have not been smoothed).

The variation in boron $K$ edge and carbon $K$-edge intensities is related to changes in the composition of the reactant gases used to generate the films. A compositional analysis from the boron/carbon $x$-ray emission intensity ratios as a function of reactants gas composition is shown in Fig. 1 (bottom) after correcting for self-absorption and radiative cross section. ${ }^{38}$ The results, as noted previously, are in qualitative (though not quantitative) agreement with the Auger electron spectroscopy results (also corrected for attenuation and Auger electron cross section).

Some samples with oxygen contamination show additional features near 182 and $164 \mathrm{eV}$ transition energies. These features are likely to reflect the higher oxygen content of films and may arise from the hybridization of the boron $2 p$ states with oxygen $2 p$ and $2 s$ levels. The comparison with samples without an oxygen signal provide the basis for this postulate. From the carbon $K$-emission data, there is some suggestion that oxygen contaminated films may have graphitic precipitates, though the pure boron carbide samples appear homogeneous in both the boron $1 \mathrm{~s}$ and carbon $1 s$ data (Figs. 5 and 6). The samples of boron carbide made by PECVD appear to be single phase.

\section{SUMMARY}

Boron carbide thin films fabricated by PECVD from $\mathrm{B}_{5} \mathrm{H}_{9}+\mathrm{CH}_{4}$ appear compositionally homogeneous over a wide composition range. Using these precursors, microcrystalline boron carbide films can be deposited on $\mathrm{Si}(111)$ surface at lower temperatures than by using other precursors. We speculate that this new boron carbide thin film material may have high resistivity because the indirect evidence indicates that there are no precipitates of carbon or other conductive phase.

\section{ACKNOWLEDGMENTS}

This work was funded by the National Science Foundation (Grant No. DDM-92-22880) and Air Force Office of Scientific Research.

${ }^{1}$ S. Lee, J. Mazurowski, G. Ramseyer, and P. A. Dowben, J. Appl. Phys. 72, 4925 (1992).

${ }^{2}$ J. Mazurowski, S. Lee, G. Ramseyer, and P. A. Dowben, MRS Proc. 242, 637 (1992).

${ }^{3}$ S. Lee and P. A. Dowben, Appl. Phys. A (in press); S. Lee, T. Ton, D. Zych, and P. A. Dowben, MRS Symp. Proc. 283, 483 (1993).

${ }^{4}$ B. Morosin, A. W. Mullendore, D. Emin, and G. A. Slack, AIP Conf. Proc. 140, 70 (1986).

${ }^{5}$ T. M. Duncan, AIP Conf. Proc. 140, 177 (1986).

${ }^{6}$ T. L. Aselage, D. Emin, C. Wood, I. Mackinnon, and I. Howard, MRS Symp. Proc. 97, 27 (1987).

${ }^{7}$ B. Morosin, T. L. Aselage, and R. S. Feigelson, MRS Symp. Proc. 97, 145 (1987).

${ }^{8}$ T. L. Aselage and D. Emin, AIP Proc. 213, 177 (1991).

${ }^{9}$ T. Lundström, AIP Conf. Proc. 213, 186 (1991).

${ }^{10}$ B. Morosin, T. L. Aselage, and D. Emin, AIP. Conf. Proc. 213, 193 (1991).

${ }^{11}$ H. L. Yakel, Acta Crystallogr. B 31, 1797 (1975).

${ }^{12}$ A. Kirfel, A. Gupta, and G. Will, Acta. Crystallogr. B 35, 1052 (1979); ibid. 2291 (1979); ibid. B 36, 1311 (1980).

${ }^{13} \mathrm{G}$. Will and K. H. Kossobutzki, J. Less-Common Metals 47, 43 (1976).

${ }^{14}$ G. Will, A. Kirfel, and A. Gupta, J. Less-Common Metals 67, 13 (1979).

${ }^{15}$ K. Ploog, J. Cryst. Growth 24/25, 197 (1974).

${ }^{16} \mathrm{M}$. Olsson, S. Söderberg, B. Stridh, U. Jansson, and J. O. Carlsson, Thin Solid Films 172, 95 (1989).

${ }^{17}$ A. N. Campbell, A. W. Mullendore, D. R. Tallant, and C. Wood, MRS Symp. Proc. 97, 113 (1987).

${ }^{18}$ D. N. Kevill, T. J. Rissmann, D. Brewe, and C. Wood, J. Cryst. Growth 74, 210 (1986).

${ }^{19}$ V. Cholet, R. Herbin, and L. Vandenbulcke, Thin Solid Films 188, 143 (1990).

${ }^{20} \mathrm{M}$. Bouchacourt and F. Thevenot, J. Less-Common Metals 67, 327 (1979); ibid. 82, 219 (1981); ibid. 82, 227 (1981).

${ }^{21}$ A. K. Bandyopadhyay, F. Beuneu, L. Zuppiroli, and M. Beauvy, J. Phys. Chem. Solids 45, 207 (1984).

${ }^{22}$ T. A. Callcott, W. L. O'Brien, J. Jia, Q. Y. Dong, D. L. Ederer, R. N. Watts, and D. R. Mueller, Nucl. Instrum. Methods A 139, 128 (1992).

${ }^{23}$ T. A. Callcott, C. H. Zhang, K. L. Tsang, E. T. Arakawa, D. L. Ederer, and J. Kerner, Nucl. Instrum. Methods B 40/41, 398 (1989).

${ }^{24}$ T. A. Callcott, K. L. Tsang, C. H. Zhang, D. L. Ederer, and E. T. Arakawa, Rev. Sci. Instrum. 57, 2680 (1986).

${ }^{25}$ F. K. Perkins, M. Onellion, S. Lee, D. Li, J. Mazurowski, and P. A. Dowben, Appl. Phys. A 54, 442 (1992).

${ }^{26}$ Y.-G. Kim, P. A. Dowben, and J. T. Spencer, J. Vac. Sci. Technol. A 7, 2796 (1989).

${ }^{27}$ H. H. Madden, G. C. Nelson, and W. O. Wallace, AIP Conf. Proc. 140, 121 (1986).

${ }^{28}$ S. Lee, P. A. Dowben, A. T. Wen, A. P. Hitchcock, J. A. Glass, and J. T. Spencer, J. Vac. Sci. Technol. A 10, 881 (1992).

${ }^{29}$ S. Komatsu and Y. Moriyoshi, J. Appl. Phys. 64, 1878 (1988).

${ }^{30}$ S. Komatsu and Y. Moriyoshi, J. Appl. Phys. 66, 466 (1989).

${ }^{31}$ H. P. Klug and L. E. Alexander, $X$-ray Diffraction Procedures for Polycrystalline and Amorphous Materials, 2nd ed. (Wiley-Interscience, New York, 1974), p. 656 . 
${ }^{32}$ Y. Toyoshima, K. Arai, and A. Matsuda, J. Non-Cryst. Solids 114, 819 (1989).

${ }^{33}$ R. S. Crisp, J. Phys. F 13, 1325 (1983).

${ }^{34}$ E. B. Saloman, J. H. Hubbell, and J. H. Scofield, Atom. Data Nucl. Data Tables 38, 1 (1988).
${ }^{35}$ T. J. Peterson, Jr. and D. H. Tomboulian, Phys. Rev. 125, 235 (1962).

${ }^{36}$ W. Burghard, M. Umeno, G. Wiech, and W. Zahorowski, J. Phys. C 16, 4243 (1983).

${ }^{37}$ V. A. Fomicher, Izv. Akad. Nauk SSSR Ser. Fiz. 31, 957 (1967). 